\title{
Tumor-derived interleukin-10 as a prognostic factor in stage III patients undergoing adjuvant treatment with an autologous melanoma cell vaccine.
}

\author{
Amit Mahipal \\ Thomas Jefferson University \\ Mizue Terai \\ Thomas Jefferson University \\ David Berd \\ , Eastern Regional Medical Center, Philadelphia, PA. \\ Inna Chervoneva

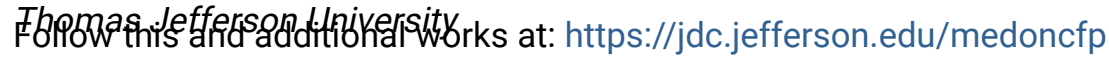

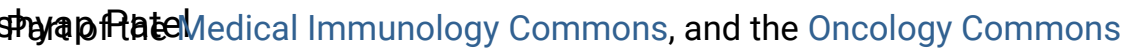

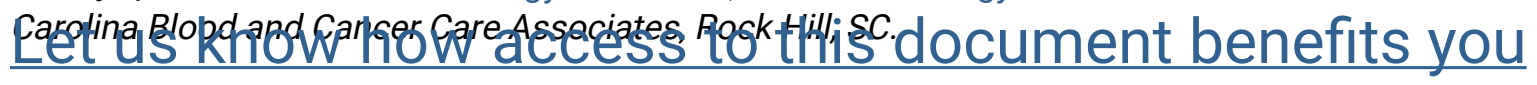

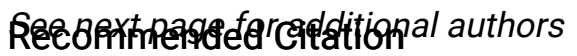

Mahipal, Amit; Terai, Mizue; Berd, David; Chervoneva, Inna; Patel, Kashyap; Mastrangelo, Michael; and Sato, Takami, "Tumor-derived interleukin-10 as a prognostic factor in stage III patients undergoing adjuvant treatment with an autologous melanoma cell vaccine." (2011). Department of Medical Oncology Faculty Papers. Paper 12.

https://jdc.jefferson.edu/medoncfp/12

This Article is brought to you for free and open access by the Jefferson Digital Commons. The Jefferson Digital Commons is a service of Thomas Jefferson University's Center for Teaching and Learning (CTL). The Commons is a showcase for Jefferson books and journals, peer-reviewed scholarly publications, unique historical collections from the University archives, and teaching tools. The Jefferson Digital Commons allows researchers and interested readers anywhere in the world to learn about and keep up to date with Jefferson scholarship. This article has been accepted for inclusion in Department of Medical Oncology Faculty Papers by an authorized administrator of the Jefferson Digital Commons. For more information, please contact: JeffersonDigitalCommons@jefferson.edu. 


\section{Authors}

Amit Mahipal, Mizue Terai, David Berd, Inna Chervoneva, Kashyap Patel, Michael Mastrangelo, and Takami Sato 


\section{As submitted to: \\ Cancer Immunology, Immunotherapy \\ And later published as: \\ Tumor-derived Interleukin-10 as a Prognostic Factor in Stage III Patients Undergoing Adjuvant Treatment with an Autologous Melanoma Cell Vaccine Volume 60, Issue 7, July 2011, Pages 1039-1045 \\ DOI: 10.1007/s00262-011-1019-1}

Amit Mahipal $^{1}$, Mizue Terai ${ }^{1,2}$, David Berd ${ }^{3}$, Inna Chervoneva ${ }^{4}$, Kashyap Patel $^{5}$, Michael

J. Mastrangelo ${ }^{1}$ and Takami Sato ${ }^{1}$

${ }^{1}$ Department of Medical Oncology, Thomas Jefferson University, Philadelphia, PA.

2 Department of Molecular and Tumor Pathology, Chiba University Graduate School of Medicine, Chiba, Japan

${ }^{3}$ Cancer Treatment Centers of America, Eastern Regional Medical Center, Philadelphia, PA.

${ }^{4}$ Division of Biostatistics, Thomas Jefferson University, Philadelphia, PA.

${ }^{5}$ Carolina Blood and Cancer Care Associates, Rock Hill, SC.

Research support: This study was supported by the Bonnie Kroll Research Fund, the Marla Brecher Research Fund, and the Eye Melanoma Research Fund at Thomas Jefferson University.

Corresponding author: Takami Sato, MD, Department of Medical Oncology, Thomas Jefferson University, 1025 Walnut Street, Suite 1024, Philadelphia, PA 19107; Tel: 215955-1195; E-mail: takami.sato@jefferson.edu

Keywords: Melanoma, interleukin-10, cytokines, cancer vaccines, tumor markers 
Running head: IL-10, a prognosticator in melanoma vaccine recipients

Presented in part at the $46^{\text {th }}$ annual meeting of the American Society of Clinical Oncology, Chicago, IL, June 4-8, 2010.

Disclaimer: David Berd owns stocks of AVAX Technologies. 


\begin{abstract}
Objectives:

Interleukin-10 (IL-10) downregulates T cell-mediated immune responses. We studied the association between IL-10 production by freshly isolated melanoma cell suspensions in vitro and overall survival in patients undergoing adjuvant treatment with a vaccine prepared from the same autologous melanoma cells modified with a hapten, dinitrophenyl (DNP).
\end{abstract}

\title{
Methods:
}

Forty-four patients with cutaneous melanoma (29 stage III and 15 stage IV) were prospectively evaluated. Tumor cells were extracted from metastatic deposits for production of DNP-modified autologous melanoma cell vaccine. Small aliquots of the melanoma cell suspensions were separated prior to vaccine processing and cultured overnight for IL-10 production. Based on a blind assessment of the distribution of IL-10 levels in the culture supernatants, a cut-off of $200 \mathrm{pg} / \mathrm{ml}$ was used to define high versus low IL-10 producers. Cox regression model was used for multivariate analysis. Overall survival was calculated using the Kaplan-Meier method and survival curves were compared with the log-rank test.

\section{Results:}

Out of 44 patients, 29 were low and 15 were high IL-10 producers. The median OS was significantly worse for high compared to low IL-10 producers (10.5 months $v 42$ months; $P=0.022$ ). In stage III patients, the multivariate hazard ratio for high versus low IL-10 producers was $2.92(95 \% \mathrm{CI}, 1.04-8.20 ; P=0.041)$. The corresponding hazard ratio in stage IV patients was 0.92 (95\% CI, 1.04-8.20; $P=0.888)$.

\section{Conclusions:}

High IL-10 production in the tumor microenvironment could be a determinant of clinical outcomes in stage III melanoma patients receiving autologous melanoma cell vaccine. 


\section{Introduction}

The cytokines produced in the tumor microenvironment are key factors in modulating an anti-tumor immune response induced by active specific immunotherapies such as a cancer vaccine. We have reported that mRNA of interleukin 10 (IL-10) was present in metastatic melanoma tissues and IL-10 was produced by melanoma cells freshly isolated from metastases [1]. Furthermore, serum IL-10 levels correlated to disease progression of patients with metastatic melanoma [1-3].

Elevated IL-10 expression has been demonstrated in various human tumors including melanoma, ovarian cancer, head and neck cancer, renal cell carcinoma, colon cancer, lymphoma and myeloma [1, 4-12]. Elevated serum IL-10 levels have been reported as a negative prognostic factor in Hodgkin and non-Hodgkin lymphomas [13, 14]. Detectable serum levels of IL-10 have also been demonstrated to be associated with poor clinical outcomes in other tumors including hepatocellular cancer, renal carcinoma, lung cancer, gastric, and colorectal carcinoma [15-18]. Preclinical data suggests that IL10 in the tumor microenvironment plays a critical role in tumor progression and metastases [8].

In this study, we investigated the correlation between the clinical outcomes of melanoma patients treated with autologous cancer vaccine and the IL-10 levels in their tumor specimens used for cancer vaccine production. We hypothesized that the production of IL-10 by melanoma cell suspensions used for cancer vaccine would reflect the IL-10 levels in the tumor microenvironment [1,5]. We further hypothesized that high IL-10 production in the tumor microenvironment is detrimental to the efficacy of cancer vaccine.

\section{Materials and Methods}

\section{$\underline{\text { Patients }}$}

The study population consisted of 44 consecutive melanoma patients who received an autologous DNP-modified melanoma cell vaccine between October 1995 and April 1996. After the surgical resection of their metastasis, all patients received a vaccine consisting of autologous melanoma cells modified with a hapten, dinitrophenyl (DNP). The DNP-modified melanoma cell cancer vaccine study was approved by Institutional 
Review Board at Thomas Jefferson University. Informed consent was obtained from all the patients participating in the study. Patients were entered onto the protocol within 30 days of surgical removal of their metastasis. The major entry criteria were as follows: sufficient amount of tumor specimens for vaccine processing $(\geq 2.5 \mathrm{~cm})$; excellent performance statues (Karnofsky score $\geq 70$ ); age $\geq 16$ years; no systemic anti-melanoma therapy within 8 weeks of study entry; and not taking corticosteroids or other immunosuppressive drugs.

\section{Cancer vaccine preparation and treatment}

The method of preparing autologous, DNP-modified vaccine and the schedule of administration of vaccine have been previously described [19, 20]. In brief, tumor cells were extracted by enzymatic dissociation of freshly obtained metastatic melanoma with collagenase and DNAase, aliquoted, frozen in a controlled-rate freezer, and stored in liquid nitrogen in a medium containing $2.5 \%$ human albumin and $10 \%$ dimethylsulfoxide until needed. On the day of treatment, an aliquot of tumor cells was thawed. Small sample of tumor cells was separated, cultured overnight and then assayed for the presence of IL-10 in the culture supernatants. The rest of the cells for vaccine production were washed, and irradiated to $25 \mathrm{~Gy}$. Then the cells were washed again and modified with DNP. This involved a 30-minute incubation of tumor cells with dinitrofluorobenzene (DNFB), followed by washing with saline. Each vaccine fell within a specified dose range of live (trypan blue-excluding) tumor cells suspended in $0.2 \mathrm{~mL}$ of Hanks solution with human serum albumin. The final (haptenized) vaccine product $\left(2.5-7.5 \times 10^{6}\right.$ cells) did not produce any IL-10. Cyclophosphamide $300 \mathrm{mg} / \mathrm{m}^{2}$ was administered 3 days prior to the first vaccine injection. The vaccine product was mixed with a titrated dose of Bacille Calmette-Guérin (BCG), and injected intra-dermally on a weekly basis for 6 times. A booster vaccine was given at 6 months if patients had no sign of recurrence. After the completion of 6 weekly vaccine treatments, patients were evaluated by history and physical examination every 2 months in years 1 and 2, every 3 months in year 3 , every 6 months in years 4 and 5 and yearly thereafter. All patients were followed for a minimum of 5 years or until death. Overall survival (OS) of individual patient was 
measured from the date of surgery to their death or last date of follow up. Patients who were alive at the time of analysis or lost to follow-up were censored.

\section{Delayed type hypersensitivity (DTH) response to melanoma cells}

Prior to and after completion of 6 weekly vaccines, patients were tested for DTH to modified and unmodified vaccine consisting of autologous melanoma cells. Skin test materials were injected intradermally into the ventral forearm. After 48 hours the maximum diameter of skin induration was measured. A positive response was defined as a maximum diameter of induration $\geq 5 \mathrm{~mm}$.

\section{$\underline{\text { Measurement of IL-10 levels }}$}

For IL-10 production, tumor-derived cells were counted under microscope and cell numbers were adjusted to $10^{6}$ live tumor cells $/ \mathrm{ml}$ based on size and morphology of cells and exclusion of dead cells by trypan blue. Two hundred microliter of tumor cell suspensions ( $2 \times 10^{5}$ tumor cells) were placed in triplicate in a 96 flat-bottomed microtiter plate in RPMI (Mediatech, Washington, DC) supplemented with 10\% fecal calf serum, 4 mM L-glutamine, $10 \mathrm{mM}$ HEPES, $1 \%$ non-essential amino acid, penicillin $\mathrm{G}$ at 100 $\mathrm{U} / \mathrm{ml}$, and streptomycin at $100 \mu \mathrm{g} / \mathrm{ml}$. Tumor cells were cultured at $37 \mathrm{C}^{\mathrm{o}}$ in $5 \% \mathrm{CO}_{2}$ incubator over night (18 hours) and supernatants were collected and stored at $-20 \mathrm{C}^{\circ}$. IL10 levels were measured by commercially available validated ELISA kit for human IL-10 (Endogen, Cambridge, MA). The sensitivity of this assay is $3 \mathrm{pg} / \mathrm{ml}$. There is no crossreactivity of this kit with other human cytokines. The mean of IL-10 levels in triplicate was used as IL-10 level for each specimen. Standard deviations of the test results in these triplicates were less than $10 \%$ of the means. In patients whose tumor specimens were tested for IL-10 production on multiple occasions, median IL-10 level was used for study analysis.

\section{$\underline{\text { Statistical analysis }}$}

All analyses were done using SAS (SAS Institute, Inc., Cary, NC) and S-Plus 8.0 (Insightful Corp., Seattle, WA) statistical software. Descriptive statistics were used to characterize the study population. The cut-off of $200 \mathrm{pg} / \mathrm{ml}$ was used to differentiate high 
versus low IL-10 producers based on the histogram (Figure 1). The histogram of the IL10 levels suggested that the distribution of IL-10 levels in these data may be viewed as a mixture of two subpopulations with different location and scale parameters, with 200 $\mathrm{pg} / \mathrm{ml}$ level as an approximate boundary or joint point of the two subpopulations. The first subpopulation (66\% of the data) is more localized and distributed on the interval (0200), while the second subpopulation (34\% of the data) has substantially higher spread over the interval (200-1000). Since the sample size is relatively small, the IL-10 levels were dichotomized using $200 \mathrm{pg} / \mathrm{ml}$ as a cutoff for statistical analysis.

The differences between proportions of patients were tested using Fisher's exact test. Univariately, OS was evaluated using Kaplan-Meier survival curves and differences in survival were tested using the log-rank test. Cox regression model was used to estimate multivariable-adjusted hazard ratios (HR) and 95\% confidence intervals (95\% CI). The final covariates used in the multivariate analysis were IL-10 levels, age, sex, stage and the interaction term between stage and IL-10 levels. The model incorporated age (dichotomized as $\geq 60$ years $v<60$ years) and gender as known prognostic factors. Proportional hazard assumptions were appropriate overall and for each covariate. The two sided p-value of 0.05 was used for statistical significance.

\section{Results}

The study population consisted of 29 stage III and 15 stage IV cutaneous melanoma patients treated with an autologous DNP-modified vaccine. The 29 stage III patients had undergone complete resection of their metastases. Two out of 15 patients with stage IV melanoma had no clinical evidence of disease after the surgery.

Although single cell melanoma suspensions were made from the same melanoma metastasis, the production of IL-10 by individual cell suspensions would be variable due to minor differences in cell preservation condition and process of vaccine production. Therefore, we tested individual melanoma cell suspensions that were obtained from the same batch of tumor specimens and used for vaccine production as long as sufficient aliquots of tumor cells suspensions were available for IL-10 measurement (median of 4 tumor cell suspensions, range 1-5). The median IL-10 level of single cell suspensions from the same batch of tumor specimens was used for study analysis. Multiple (4 or 5) 
measurements of IL-10 production were available for 34 patients. From the linear mixed effects model fitted to repeated log transformed IL-10 measures with the random effect of patient, it was estimated that the mean log transformed IL-10 level was 4.83 (125 on the original scale), within-patient standard deviation of log transformed IL-10 measures was 0.71, and between-patient standard deviation of log transformed IL-10 measures was 1.27. Thus, the coefficient of variation associated with multiple within-patient measures is 0.147 .

Levels of IL-10 produced by freshly isolated melanoma cell suspensions ranged from $5.6 \mathrm{pg} / \mathrm{ml}$ to $981.3 \mathrm{pg} / \mathrm{ml}$ with the median of $154.9 \mathrm{pg} / \mathrm{ml}$ and mean of $254.2 \mathrm{pg} / \mathrm{ml}$. As described in the statistical analysis section, an IL-10 level of $200 \mathrm{pg} / \mathrm{ml}$ was taken as a cutoff to differentiate low and high IL-10 producers. By this definition, 29 patients (66\%) were low IL-10 producers $(<200 \mathrm{pg} / \mathrm{ml})$ and 15 patients $(34 \%)$ were high IL-10 producers $(\geq 200 \mathrm{pg} / \mathrm{ml})$. The median follow up time was 125 months (10.4 years). Baseline characteristics of the study population are summarized in Table 1. The differences in the baseline characteristics were not statistically significant in two groups. Low IL-10 producers had a higher proportion of patients with stage III disease (72\% $v 53 \%$ ) although this is not statistically significant $(P=0.315)$. Additionally, the cohort of IL-10 low producers included more patients with ages older than 60 years, compared to those with high IL-10 producers (38\% v 20\%, respectively, $P=0.314)$. The median age of patients in the low and high IL-10 producers was 55 years (range: 23 to 81 years) and 57 years (range: 34 to 75 years) respectively. Seven patients (24\%) in low IL-10 producers and 2 patients $(13 \%)$ in high IL-10 producers group had received prior treatment with chemotherapy, radiation, interferon, immunotherapy or a combination thereof $(P=0.695)$. In stage III melanoma patients, there were no significant differences among the two groups with respect to the original site of tumor and nodal status.

The univariate analysis of the potential prognostic variables indicated that the stage of the disease was the major determinant of survival (Table 2). The median OS of patients with stage III and stage IV disease was 55.8 months and 12.3 months respectively $(P<0.001)$. The DTH response to unmodified autologous melanoma cells was not a significant prognostic determinant of OS, although there is a tendency of better survival in patients who developed a positive DTH response to melanoma cells after 
vaccine treatments. The levels of tumor-derived IL-10 are also significant prognostic factor for survival. The median OS was significantly longer for low IL-10 producers as compared to high IL-10 producers (42 months $v 10.5$ months, $P=0.022$ ). Figures 2 and 3 demonstrate the Kaplan-Meier survival curves stratified by levels of IL-10 in tumor cell suspensions. It is of note that the impact of tumor-derived IL-10 on survival was more prominent in stage III patients although the difference was not statistically significant (median OS for low IL-10 producers and high IL-10 producers was 84 months and 9.7 months respectively; $P=0.073$ ). For stage IV patients, there was no significant difference between low and high IL-10 producers (13.7 months $v 10.5$ months, $P=0.624)$.

To further investigate the impact of tumor-derived IL-10 on OS, a multivariate analysis was done using Cox proportional hazard model (Table 3). The univariate analysis suggested possible association between IL-10 levels and stage. Therefore, the Cox model incorporated interaction between the stage and IL-10 level. For stage III patients, the HR for high $v$ low IL-10 producers was 2.92 (95\% CI: $1.04-8.20, P=0.041)$. In stage IV patients, the corresponding HR of 0.92 (95\% CI: $0.28-3.00, P=0.888$ ) was not statistically significant. Furthermore, the difference in OS between stage III and IV is only seen in low IL-10 producers. In low IL-10 producers, the HR for stage IV $v$ stage III was 4.95 (95\% CI: 1.74-14.09, $P=0.003)$. In contrast, the corresponding HR for stage IV $v$ III in high IL-10 producers was 1.56 (95\% CI: 0.51-4.81, $P=0.440)$.

\section{Discussion}

Therapeutic vaccines for the treatment of cancer aim to induce or boost T-cell immunity against tumor-specific or tumor-associated antigens. It is the general consensus that cancer vaccine could elicit a $\mathrm{T}$ cell immune response against cancer antigens that were used for vaccine treatment [21]. However, there is significant discrepancy between development of systemic immunity against targeted antigens and clinical outcome of cancer vaccine treatments. Furthermore, the presence of vaccine-elicited cytotoxic T lymphocytes in tumors expressing the targeted epitope also has been demonstrated without tumor regression [22]. It has been speculated that the discrepancy between increased numbers of tumor-specific $\mathrm{T}$ cells after cancer vaccine administration and the 
lack of clinical response might be explained by the interaction between cancer cells and the host immune system at the tumor site. Our current study indicates that tumor-derived IL-10 might be one of the factors to hamper the efficacy of cancer vaccine.

IL-10 has been proposed to modulate anti-tumor immune response by itself or in conjunction with other cytokines such as transforming growth factor (TGF)-beta. IL-10 is known to play a role in down regulating the expression of Th1 cytokines, thus augmenting the immunosuppressive activity of TGF-beta [23, 24]. IL-10 suppresses the T-cell immune response against melanoma cells by down regulating expression of MHC class I, class II and ICAM-1 (RW.ERROR - Unable to find reference:103). IL-10 also down regulates co-stimulatory molecules such as CD 40 expression on dendritic cells in tumor microenvironment and suppresses their maturation and functions [25]. Dendritic cells derived from patients with progressive metastatic melanoma induce anergy in helper $\mathrm{T}$ cells [26]. Overexpression of IL-10 in IL-10 transgenic mice has been demonstrated to limit the ability of these mice to control the growth of immunogenic tumors [27]. Furthermore, IL-10 has an inhibitory effect on CTLA-4 blockade for tumor-eradicating immunity. It has been reported that anti-CTLA-4 antibody alone may not provide therapeutic benefit in patients with a tumor that produces IL-10 [28]. These experiments support the critical role of IL-10 in the tumor microenvironment in modulating anti-tumor immune response.

In this study, high IL-10 levels in metastatic melanoma tissues are associated with poorer survival in stage III melanoma patients treated with DNP-modified autologous melanoma cell vaccine. However, the association between IL-10 levels and survival was not seen in stage IV patients. Tumor burden is important in immunotherapy and it is possible that vaccine itself might not have been effective in stage IV patients who had a residual clinically detectable tumor. In fact, $87 \%$ of stage IV patients had radiologically or clinically detectable disease after the surgery in this study. Since most patients died from progression of disease within 2 years, the therapeutic effect of vaccine was likely modest in stage IV patients. It is also possible that due to fewer number of stage IV patients in this study, the influence of IL-10 could not be accurately evaluated. Additionally, the multivariate analysis indicates that difference in survival between stage III and IV patients treated with DNP-modified autologous melanoma cell vaccine was 
only seen in low IL-10 producers. The better survival in stage III patients, compared to stage IV patients, was not seen in high IL-10 producers. This observation may suggest the detrimental effect of IL-10 in stage III patients who were treated with DNP-modified melanoma cell vaccine. Our study indicates that the tumor-derived IL-10 would affect the efficacy of autologous melanoma cell vaccine in stage III patients although appropriate control (patients not receiving vaccine) should be included in a future large-scale clinical trial to support this conclusion.

The majority of patients in this study had one large tumor $(>2.5 \mathrm{~cm})$ removed for the vaccine production. Furthermore, stage III patients were clinically disease free after surgical removal of lymph node metastasis; therefore, we were not able to test various tumor specimens from the same patients. It would be possible that the production of IL10 might be different in tumors in a different location; however, we assume that the tendency of IL-10 production (high or low) would be most likely similar since they are synchronous systemic metastases from the same primary cutaneous melanoma.

The ability of IL-10 to suppress antitumor immunity is confounded by observations indicating that IL-10 may promote antitumor immunity under other conditions in animal models [26, 29, 30]. Despite conflicting data obtained from artificially induced IL-10 in mice models, our clinical observations [1] as well as number of other studies indicate that serum IL-10 levels are correlated with adverse clinical outcomes in patients with melanoma and other tumors [8, 13-18]. Our current study also supports the potential detrimental effects of tumor-derived IL-10 on autologous melanoma cell vaccine.

In summary, we have demonstrated first in human that tumor-derived IL-10 might predict the outcome of autologous cancer vaccine. Our data suggest that the effect of autologous vaccine in stage III melanoma patients may be enhanced by addition of an antagonist of IL-10. In fact, we have developed immunoadhesins for IL-10 by combining the extracellular domain of human IL-10 receptor 1 with the Fc regions of human $\mathrm{IgG} 1$ heavy chain [31]. The IL-10 immunoadhesins efficiently block the biologic activity of human IL-10 produced by melanoma cells in vitro. The IL-10 immunoadhesins can be administered by either intra-tumorally or systemically to facilitate the induction of antitumor immune response after cancer vaccine. The blocking of IL-10 in tumor 
microenvironment itself may also be a useful therapeutic strategy in melanoma patients. However, due to the complexity of biological effects of IL-10 in the immune system, this strategy should be tested in carefully designed preclinical and clinical models. 


\section{References}

1. Sato T, McCue P, Masuoka K, Salwen S, Lattime EC, Mastrangelo MJ, Berd D (1996) Interleukin 10 production by human melanoma. Clin Cancer Res 2(8):1383-1390 2. Nemunaitis J, Fong T, Shabe P, Martineau D, Ando D (2001) Comparison of serum interleukin-10 (IL-10) levels between normal volunteers and patients with advanced melanoma. Cancer Invest 19(3):239-247

3. Boyano MD, Garcia-Vazquez MD, Lopez-Michelena T, Gardeazabal J, Bilbao J, Canavate ML, Galdeano AG, Izu R, Diaz-Ramon L, Raton JA, Diaz-Perez JL (2000) Soluble interleukin-2 receptor, intercellular adhesion molecule-1 and interleukin-10 serum levels in patients with melanoma. Br J Cancer 83(7):847-852

4. Chen Q, Daniel V, Maher DW, Hersey P (1994) Production of IL-10 by melanoma cells: examination of its role in immunosuppression mediated by melanoma. Int J Cancer 56(5):755-760

5. Dummer W, Becker JC, Schwaaf A, Leverkus M, Moll T, Brocker EB (1995) Elevated serum levels of interleukin-10 in patients with metastatic malignant melanoma. Melanoma Res 5(1):67-68

6. Fortis C, Foppoli M, Gianotti L, Galli L, Citterio G, Consogno G, Gentilini O, Braga M (1996) Increased interleukin-10 serum levels in patients with solid tumours. Cancer Lett 104(1):1-5

7. Kruger-Krasagakes S, Krasagakis K, Garbe C, Schmitt E, Huls C, Blankenstein T, Diamantstein T (1994) Expression of interleukin 10 in human melanoma. Br J Cancer 70(6):1182-1185 
8. Yue FY, Dummer R, Geertsen R, Hofbauer G, Laine E, Manolio S, Burg G (1997) Interleukin-10 is a growth factor for human melanoma cells and down-regulates HLA class-I, HLA class-II and ICAM-1 molecules. Int J Cancer 71(4):630-637

9. Ekmekcioglu S, Okcu MF, Colome-Grimmer MI, Owen-Schaub L, Buzaid AC, Grimm EA (1999) Differential increase of Fas ligand expression on metastatic and thin or thick primary melanoma cells compared with interleukin-10. Melanoma Res 9(3):261272

10. Pisa P, Halapi E, Pisa EK, Gerdin E, Hising C, Bucht A, Gerdin B, Kiessling R (1992) Selective expression of interleukin 10, interferon gamma, and granulocytemacrophage colony-stimulating factor in ovarian cancer biopsies. Proc Natl Acad Sci U S A 89(16):7708-7712

11. Gotlieb WH, Abrams JS, Watson JM, Velu TJ, Berek JS, Martinez-Maza O (1992) Presence of interleukin 10 (IL-10) in the ascites of patients with ovarian and other intraabdominal cancers. Cytokine 4(5):385-390

12. Avradopoulos K, Mehta S, Blackinton D, Wanebo HJ (1997) Interleukin-10 as a possible mediator of immunosuppressive effect in patients with squamous cell carcinoma of the head and neck. Ann Surg Oncol 4(2):184-190

13. Blay JY, Burdin N, Rousset F, Lenoir G, Biron P, Philip T, Banchereau J, Favrot MC (1993) Serum interleukin-10 in non-Hodgkin's lymphoma: a prognostic factor. Blood 82(7):2169-2174

14. Bohlen H, Kessler M, Sextro M, Diehl V, Tesch H (2000) Poor clinical outcome of patients with Hodgkin's disease and elevated interleukin-10 serum levels. Clinical 
significance of interleukin-10 serum levels for Hodgkin's disease. Ann Hematol 79(3):110-113

15. Chau GY, Wu CW, Lui WY, Chang TJ, Kao HL, Wu LH, King KL, Loong CC, Hsia CY, Chi CW (2000) Serum interleukin-10 but not interleukin-6 is related to clinical outcome in patients with resectable hepatocellular carcinoma. Ann Surg 231(4):552-558 16. De Vita F, Orditura M, Galizia G, Romano C, Lieto E, Iodice P, Tuccillo C, Catalano G (2000) Serum interleukin-10 is an independent prognostic factor in advanced solid tumors. Oncol Rep 7(2):357-361

17. De Vita F, Orditura M, Galizia G, Romano C, Infusino S, Auriemma A, Lieto E, Catalano G (1999) Serum interleukin-10 levels in patients with advanced gastrointestinal malignancies. Cancer 86(10):1936-1943

18. Wittke F, Hoffmann R, Buer J, Dallmann I, Oevermann K, Sel S, Wandert T, Ganser A, Atzpodien J (1999) Interleukin 10 (IL-10): an immunosuppressive factor and independent predictor in patients with metastatic renal cell carcinoma. Br J Cancer 79(78):1182-1184

19. Berd D, Mastrangelo MJ, Sato T (2005) Calculation of survival of patients with stage III melanoma. J Clin Oncol 23(36):9427; author reply 9428

20. Berd D, Sato T, Maguire HC,Jr, Kairys J, Mastrangelo MJ (2004)

Immunopharmacologic analysis of an autologous, hapten-modified human melanoma vaccine. J Clin Oncol 22(3):403-415

21. Keilholz U, Weber J, Finke JH, Gabrilovich DI, Kast WM, Disis ML, Kirkwood JM, Scheibenbogen C, Schlom J, Maino VC, Lyerly HK, Lee PP, Storkus W, Marincola F, Worobec A, Atkins MB (2002) Immunologic monitoring of cancer vaccine therapy: 
results of a workshop sponsored by the Society for Biological Therapy. J Immunother 25(2):97-138

22. Marincola FM, Jaffee EM, Hicklin DJ, Ferrone S (2000) Escape of human solid tumors from T-cell recognition: molecular mechanisms and functional significance. Adv Immunol 74:181-273

23. Cottrez F, Groux H (2001) Regulation of TGF-beta response during T cell activation is modulated by IL-10. J Immunol 167(2):773-778

24. Lucey DR, Clerici M, Shearer GM (1996) Type 1 and type 2 cytokine dysregulation in human infectious, neoplastic, and inflammatory diseases. Clin Microbiol Rev 9(4):532-562

25. Shurin MR, Yurkovetsky ZR, Tourkova IL, Balkir L, Shurin GV (2002) Inhibition of CD40 expression and CD40-mediated dendritic cell function by tumor-derived IL-10. Int J Cancer 101(1):61-68

26. Groux H, Cottrez F, Rouleau M, Mauze S, Antonenko S, Hurst S, McNeil T, Bigler M, Roncarolo MG, Coffman RL (1999) A transgenic model to analyze the immunoregulatory role of IL-10 secreted by antigen-presenting cells. J Immunol 162(3):1723-1729

27. Hagenbaugh A, Sharma S, Dubinett SM, Wei SH, Aranda R, Cheroutre H, Fowell DJ, Binder S, Tsao B, Locksley RM, Moore KW, Kronenberg M (1997) Altered immune responses in interleukin 10 transgenic mice. J Exp Med 185(12):2101-2110 28. Jovasevic VM, Gorelik L, Bluestone JA, Mokyr MB (2004) Importance of IL-10 for CTLA-4-mediated inhibition of tumor-eradicating immunity. J Immunol 172(3):14491454 
29. Adris S, Klein S, Jasnis M, Chuluyan E, Ledda M, Bravo A, Carbone C, Chernajovsky Y, Podhajcer O (1999) IL-10 expression by CT26 colon carcinoma cells inhibits their malignant phenotype and induces a $\mathrm{T}$ cell-mediated tumor rejection in the context of a systemic Th2 response. Gene Ther 6(10):1705-1712

30. Huang S, Ullrich SE, Bar-Eli M (1999) Regulation of tumor growth and metastasis by interleukin-10: the melanoma experience. J Interferon Cytokine Res 19(7):697-703

31. Terai M, Tamura Y, Alexeev V, Ohtsuka E, Berd D, Mastrangelo MJ, Sato T (2009) Human interleukin 10 receptor $1 / \mathrm{IgG} 1-\mathrm{Fc}$ fusion proteins: immunoadhesins for human IL-10 with therapeutic potential. Cancer Immunol Immunother 58(8):1307-1317 
Table 1: Baseline characteristics of the patients

\begin{tabular}{|c|c|c|c|}
\hline & Low IL-10 producers & High IL-10 producers & $\mathrm{P}$-value \\
\hline Number of patients & 29 & 15 & \\
\hline Median age (range), years & $55(23-81)$ & $57(34-75)$ & \\
\hline \multicolumn{4}{|l|}{ Age } \\
\hline$\geq 60$ years & $11(38 \%)$ & $3(20 \%)$ & 0.314 \\
\hline$<60$ years & $18(62 \%)$ & $12(80 \%)$ & \\
\hline \multicolumn{4}{|l|}{ Sex } \\
\hline Male & $17(59 \%)$ & $10(67 \%)$ & 0.748 \\
\hline Female & $12(41 \%)$ & $5(33 \%)$ & \\
\hline \multicolumn{4}{|l|}{ Stage } \\
\hline III & $21(72 \%)$ & $8(53 \%)$ & 0.315 \\
\hline IV & $8(28 \%)$ & $7(47 \%)$ & \\
\hline Prior therapy & $7(24 \%)$ & $2(13 \%)$ & 0.695 \\
\hline \multicolumn{4}{|l|}{ DTH response } \\
\hline$\geq 5 \mathrm{~mm}$ & $15(52 \%)$ & $11(73 \%)$ & 0.299 \\
\hline$<5 \mathrm{~mm}$ & $11(38 \%)$ & $3(20 \%)$ & \\
\hline Unknown & $3(10 \%)$ & $1(7 \%)$ & \\
\hline
\end{tabular}

Abbreviations: DTH, delayed type hypersensitivity 
Table 2: Univariate analysis of effect of variables on OS

\begin{tabular}{lccc}
\hline \multicolumn{1}{c}{ Parameter } & Median OS (months) & $95 \%$ CI & $P$ \\
\hline Age & & & \\
$\quad \geq 60$ years & 15.1 & 10.5 to 84.0 & 0.663 \\
$\quad<60$ years & 19.0 & 9.7 to 56.5 & \\
Sex & & & \\
$\quad$ Male & 13.6 & 9.7 to 52.6 & 0.169 \\
$\quad$ Female & 20.2 & 12.3 to $\mathrm{NR}$ & \\
Stage & & & \\
$\quad$ III & 55.8 & 13.1 to $\mathrm{NR}$ & $<0.001$ \\
IV & 12.3 & 7.7 to 17.9 & \\
Prior therapy & & & \\
$\quad$ Yes & 13.7 & 4.7 to 18.5 & 0.294 \\
$\quad$ No & 20.2 & 12.3 to 56.5 & \\
DTH response & & & \\
$\quad \geq 5 \mathrm{~mm}$ & 26.7 & 13.1 to 84.0 & 0.395 \\
$\quad<5 \mathrm{~mm}$ & 15.7 & 7.5 to 55.8 & \\
IL-10 levels & & & \\
$\quad \geq 200 \mathrm{pg} / \mathrm{ml}$ & 10.5 & 7.5 to 13.1 & 0.022 \\
$<200 \mathrm{pg} / \mathrm{ml}$ & 42.0 & 13.7 to $\mathrm{NR}$ & \\
\hline
\end{tabular}

Abbreviations: OS, overall survival; DTH, delayed type hypersensitivity; NR, not reached 
Table 3. Multivariate analysis of variables

\begin{tabular}{lccc}
\hline Factor & Hazard Ratio & $95 \%$ CI & $P$ \\
\hline Age $\geq$ 60 years $v$ age $<60$ years & 1.23 & 0.54 to 2.83 & 0.621 \\
Male $v$ female & 1.79 & 0.81 to 3.95 & 0.151 \\
Stage IV $v$ III in high IL-10 & 1.56 & 0.51 to 4.81 & 0.440 \\
Stage IV $v$ III in low IL-10 & 4.95 & 1.74 to 14.09 & 0.003 \\
High IL-10 $v$ low IL-10 in stage III & 2.92 & 1.04 to 8.20 & 0.041 \\
High IL-10 $v$ low IL-10 in stage IV & 0.92 & 0.28 to 3.00 & 0.888 \\
\hline
\end{tabular}




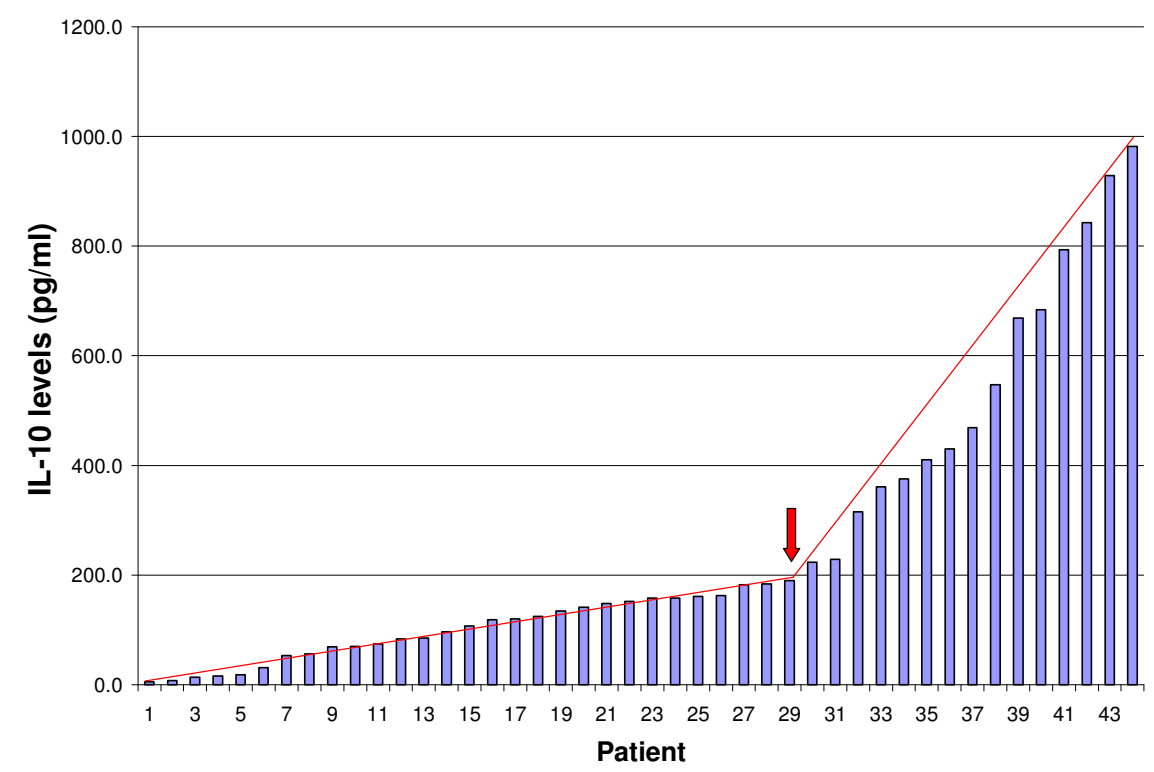

Figure 1. Production of IL-10 by tumor cell suspensions. The arrow denotes the cutoff point (IL-10 level of $200 \mathrm{pg} / \mathrm{ml}$ ) to differentiate low versus high IL-10 producers. 


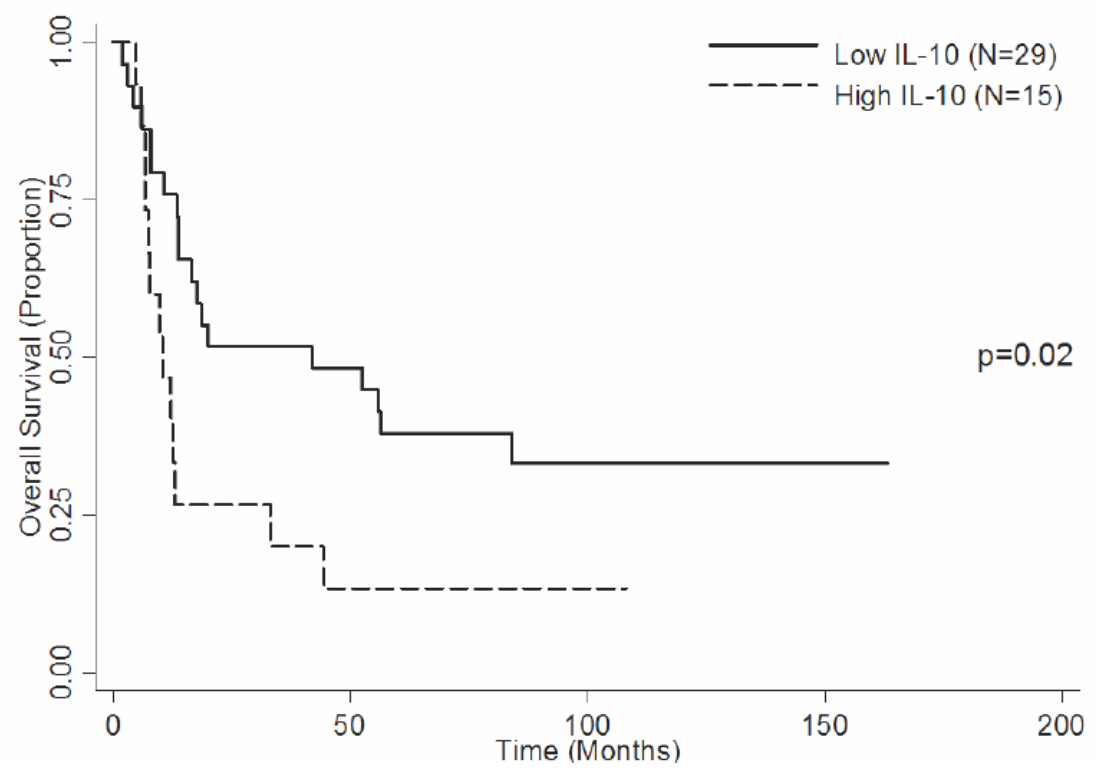

Figure 2. Overall survival of patients treated with autologous, DNP-modified vaccine stratified by IL-10 levels. 


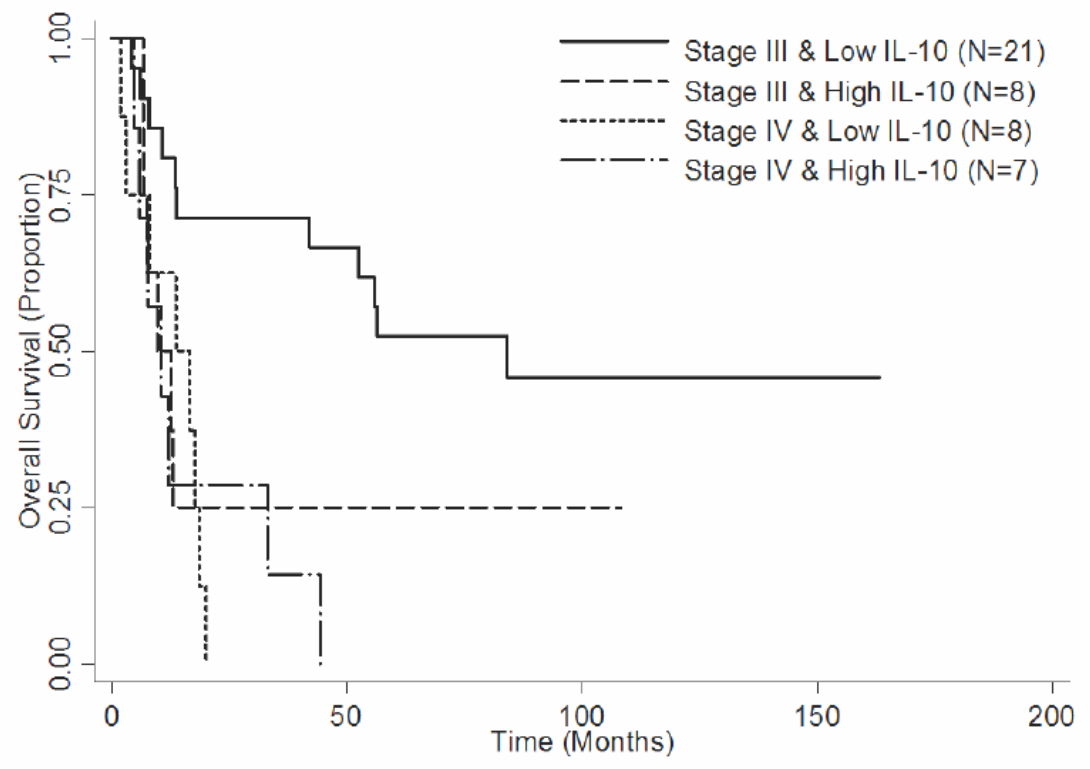

Figure 3. Overall survival of melanoma patients stratified by stage and IL-10 levels. The p-values for the differences in survival among low and high IL-10 producers in stage III and stage IV patients were 0.073 and 0.624 respectively. 